\title{
O Programa Institucional de Bolsa de Iniciação à Docência - PIBID/Matemática/ UFMT auxiliando na Formação Inicial
}

The Institutional Program of Scholarship for Initiation to Teaching (PIBID)/Mathematics/Federal University of Mato Grosso (UFMT) helping in initial teacher training

Sergio Antonio Wielewski ${ }^{1}$

Luzia Aparecida Palaro²

Gladys Denise Wielewski

\section{RESUMO}

Docentes que atuam em cursos de Licenciatura vêm a alguns anos discutindo a dicotomia entre teoria e prática na formação de professores. Visando diminuir esta dicotomia indagou-se: que ações complementares além do estágio supervisionado podem ser desenvolvidas na formação de professores de modo a estabelecer e ampliar a relação entre teoria e prática ao ensinar matemática na educação básica? Acreditando que o desenvolvimento de ações nesta perspectiva pode contribuir para melhorar a formação do professor de matemática, realizou-se uma pesquisa para saber se o Pibid poderia auxiliar na formação inicial de professores de matemática pela pesquisa. Utilizou-se metodologia qualitativa em dois momentos: um para a coleta de dados na escola realizada pelos sujeitos da pesquisa, bolsistas do Pibid-Matemática/UFMT, recorrendo a questionários de diagnóstico da escola, de professores de matemática e alunos, entrevistas e planejamento de atividades, e outro para a coleta de dados dos pesquisadores sobre a atuação dos bolsistas, recorrendo a reuniões em grupo, depoimentos, questionários, observações, relatórios. Os bolsistas puderam conhecer a escola no aspecto administrativo/pedagógico, identificar dificuldades no ensino e na aprendizagem da matemática, elaborar, desenvolver e avaliar ações para superar as dificuldades. Percebeu-se pela atuação dos bolsistas que a dicotomia entre teoria e prática foi amenizada. Palavras-chave: Formação inicial, iniciação à docência, PibidMatemática/UFMT-Cuiabá, teoria e prática.

\section{ABSTRACT}

Brazilian professors who work in teacher training courses have, for some time, been discussing the dichotomy between theory and practice in forming teachers. Seeking to reduce this dichotomy, a question was raised: what complementary actions besides the supervised practice teaching can be carried out in preparing teachers as a means to establish and expand the relation between theory and practice when teaching mathematics at basic level? Believing that the development of actions in this perspective can contribute to improve the training of the mathematics teacher, a research was conducted to verify if the Pibid could help in the initial training of mathematics teachers through research. Qualitative methodology was used in two moments: one for the collection of data at the school, which was done by the subjects, scholars in the Pibid-Mathematics/UFMT, using diagnostic questionnaires about the school, the mathematic teachers, and the students, interviews and the planning of activities, the other for the collection of data by the researchers about the performance of the scholars using meetings with the group, testimonials, questionnaires, observation, reports. The student teachers were able to get to know the school in the administrative/pedagogical aspect, to identify the difficulties in the teaching and learning of mathematics, and to prepare, develop, and evaluate actions to overcome those difficulties. It was possible to notice, by the performance of the scholars that the dichotomy between theory and practice was diminished.

Keywords: Initial teacher training, initiation to teaching, Pibid-Mathematics/UFMT-Cuiabá, theory and practice.

\footnotetext{
${ }^{1}$ Coordenador de área do subprojeto PIBID/Matemática/UFMT/Cuiabá.

${ }^{2}$ Coordenadora Institucional do PIBID/UFMT 2011-2012.

${ }^{3}$ Professora voluntária do subprojeto PIBID/Matemática/UFMT/Cuiabá.
} 


\section{Introdução}

Professores que atuam em cursos de licenciatura no Brasil têm, nos últimos anos, intensificado as discussões a respeito da relação entre teoria e prática, uma vez que essa tem se mostrado uma necessidade intrínseca na formação profissional. Nos Cursos de Licenciaturas em Matemática sempre houve muita discussão teórica sobre formação docente, mas poucas evidências empíricas que referenciassem as práticas e as políticas para formação.

As Diretrizes Curriculares Nacionais para a formação de professores da educação básica em nível superior recomendam que:

A aquisição de competências requeridas do professor deverá ocorrer mediante uma ação teórico-prática, ou seja, toda sistematização teórica articulada com o fazer e todo fazer articulado com a reflexão (BRASIL, 2001, p. 29).

No Curso de Licenciatura Plena em Matemática da Universidade Federal de Mato Grosso-Cuiabá, a prática sempre foi vivenciada, prioritariamente, por meio das disciplinas de estágio supervisionado, realizadas somente nos últimos semestres da graduação.

Com a intensificação da globalização, tem-se reforçado cada vez mais a necessidade da formação de um profissional que seja competente tanto nos aspectos teórico quanto prático, ou seja, formação que contemple conhecimentos específicos e pedagógicos proporcionando a compreensão da ação educativa para o desencadeamento de novas práticas pedagógicas fundamentadas teoricamente. Essa necessidade levou à discussão de problemas referentes à formação de professores de matemática que passou a ser evidenciada e divulgada por meio de pesquisas, tornando a licenciatura um dos focos de investigação, culminando na avaliação dos cursos, na elaboração de propostas de reestruturações curriculares e discussões acerca da relação teoria e prática.

Nacarato e Paiva (2006) complementam essa discussão alegando que a formação de professores se constitui pela definição de formação, quais seus objetivos e funções, qual o perfil final do profissional, quais conteúdos matemáticos e pedagógicos propostos; quais os saberes que esse professor deve ter para atuar na profissão.

Assim, com a evolução da sociedade, espera-se que os professores sejam profissionais dinâmicos, criativos, com iniciativa própria, questionadores e capazes de encontrar meios para superar desafios. Então, apropriar-se de conhecimentos ligados à prática pedagógica passa a ser crucial para os professores, uma vez que sua atuação docente requer ações educativas, que sejam criativas e planejadas priorizando a participação dentro e também fora da escola. Nesse sentido, a licenciatura é considerada como um espaço para formar um futuro professor que saiba Matemática e, ao mesmo tempo, que saiba como ensinar essa Matemática na escola de Educação Básica.

Alguns autores discutem a função do estágio supervisionado e o modo como vem sendo efetivado em cursos de licenciatura. Piconez (1991), por exemplo, ressalta que o estágio supervisionado vem se desenvolvendo como um componente teórico-prático, uma vez que possui duas caracterizações: uma sendo idealizada, de cunho teórico, subjetivo, e outra sendo real preocupada com o material, o social e a prática, inserida no contexto da escola. 
Para Castro (2000), a formação do professor deve propiciar vivências em diferentes situações de ensino e aprendizagem, bem como de demais dinâmicas de interação entre professor-aluno.

Gómez (1995, p.112) ressalta que:

O pensamento prático do professor não pode ser ensinado, mas pode ser aprendido. Aprende-se fazendo e reflectindo na e sobre a acção. Através da prática é possível apoiar e desenvolver o pensamento prático, graças a uma reflexão conjunta (e recíproca) entre o aluno-mestre e o professor ou o tutor.

A prática tem mostrado que para superar essa problemática no processo de formação de professores não basta apenas a elaboração de uma proposta avançada de estágio. "Torna-se necessário que tanto o corpo docente quanto o discente tomem o trabalho como o eixo articulador da relação teoria-prática introduzindo o aluno-estagiário no universo da pesquisa a partir da atividade prática vivenciada nos sistemas de ensino formal e informal" (FREITAS, 1996).

Apesar das discussões referentes a dicotomia entre teoria e prática terem avançado nos cursos de licenciatura e o estágio supervisionado estar propiciando experiências significativas visando minimizar essa dicotomia, este ainda não está sendo suficiente para garantir a formação de profissionais que consigam dar conta dos inúmeros problemas de conhecimento empírico e científico, de ordem social, cultural, relacional detectados nas escolas. As 400 horas destinadas atualmente ao estágio supervisionado não são suficientes para desenvolver práticas científico-pedagógicas e nem para vivenciar experiências que caracterizam o professor como pesquisador de sua prática.

Diante disso, indaga-se que ações complementares além do estágio supervisionado podem ser desenvolvidas na formação de professores de modo a estabelecer e ampliar a relação entre teoria e prática ao ensinar matemática na educação básica?

\section{Metodologia}

Recentemente no Brasil, por iniciativa da Coordenação de Aperfeiçoamento de Professores do Ensino Superior (CAPES), órgão integrante do Ministério de Educação e Cultura (MEC), no $2^{\circ}$ semestre de 2007, é proposto o Programa Institucional de Bolsa de Iniciação à Docência (PIBID), cujo objetivo é o aperfeiçoamento e a valorização da formação de professores para a educação básica. Em parceria com as escolas de educação básica as Instituições de Educação Superior, por meio do PIBID desenvolvem projetos de iniciação à docência. Os alunos e professores das licenciaturas envolvidos nos projetos, bem como os professores da Educação Básica também participantes, recebem bolsas concedidas pela CAPES que atualmente se aproximam de 50.000 unidades em todo o país, com previsão de mais de 70.000 no ano de 2014.

Por meio desses projetos, na Universidade Federal de Mato Grosso (UFMT), alunos de licenciaturas são inseridos no contexto das escolas públicas do ensino médio, desde o início da sua graduação, desenvolvendo atividades científico-pedagógicas orientados e acompanhados por professores das licenciaturas e por professores das Escolas envolvidos no processo, perfazendo uma carga horária de 20 horas semanais.

Na UFMT, o projeto institucional conta com 28 licenciaturas participantes do PIBID, distribuídas nos quatro campi (Cuiabá, Rondonópolis, Barra do Garças e Sinop). 
O Curso de Licenciatura Plena em Matemática da UFMT do campus Cuiabá participa do PIBID com 01 Coordenador de Área que é professor do Curso atuando na área de Ensino, 06 alunos bolsistas e 01 supervisor (professor) de uma escola de ensino médio na qual o projeto é desenvolvido.

Com essa iniciativa abriram-se duas possibilidades de pesquisa de caráter qualitativo: uma para os bolsistas e outra para o professor coordenador. Os bolsistas pesquisam sua própria prática docente, com a finalidade de compreender sua realidade educacional para transformá-la, o que poderá acarretar numa melhoria de sua prática científico-pedagógica e a de seus colegas. O coordenador, por sua vez, desenvolve uma pesquisa científica com o objetivo de registrar e compreender a relação teoria e prática no processo de formação docente dos bolsistas envolvidos. Assim, o lócus da pesquisa é a escola pública de ensino médio na qual o Pibid é desenvolvido e os sujeitos da pesquisa são os bolsistas que atuaram no projeto no período de 2009 a 2011.

Nesse processo, em que o trabalho e a pesquisa orientam a formação e o desenvolvimento das atividades, a complementaridade entre a prática e teoria estabeleceria uma relação de unidade dialética visto que o ponto de partida e de chegada do processo de formação seria a prática educacional. Dessa forma, a teoria, nessa perspectiva, deixaria de ser unicamente um conjunto de "conhecimentos sistematizados a priori, passando a ser formulada a partir das necessidades concretas da realidade educacional, a qual busca responder através da orientação de linhas de ação" (CANDAU; LELIS, 1996, p. 59).

Stenhouse (apud RAMOS, 2005) é um dos defensores da utilização da pesquisa no âmbito da escola, e alega que esta deveria ser a base do ensino dos professores. E acrescenta que realizar uma formação em pesquisa pode propiciar ao professor o desenvolvimento de uma consciência crítica de suas ações educacionais.

Com essa perspectiva de trabalho o graduando tem a possibilidade de refletir durante o processo como um todo, ou seja, antes, durante e após a prática educativa, que é o modelo de formação profissional baseado no 'ensino reflexivo' proposto por Schön (1995) e Gómez (1995).

Assim o PIBID-Matemática UFMT/Cuiabá vem se consolidando como uma alternativa e referência quanto ao suporte para a complementação da formação de alunos da Licenciatura em Matemática, cuja metodologia de trabalho prevê iniciar esses alunos bolsistas em modelos e momentos de pesquisas de cunho formativo que contemplem três eixos básicos:

1. Pesquisa histórica e contextual da identidade do professor de matemática a partir da compreensão da história do ensino, do professor de matemática e da escola em atuação;

2. Pesquisa para compreensão sobre a estrutura e funcionamento da escola nos seguintes aspectos: espaços administrativos, curriculares, sócio cultural, político etc.;

3. Pesquisa enquanto planejamento e desenvolvimento de atividades em sala de aula ou extraclasse, por meio de monitorias individuais e grupais, monitorias temáticas, tutorias, oficinas pedagógicas, cursos de formação continuada e exploração de diversos espaços e performance para a realização do ensino e aprendizagem da matemática.

Para o desenvolvimento dos eixos acima os bolsistas elaboraram instrumentos para coleta de dados da escola, dos alunos, da equipe técnico pedagógica, organizaram os dados obtidos, planejaram, desenvolveram e avaliaram ações científico-pedagógicas. Todos estes processos foram permeados por reflexões na elaboração, no e do desenvolvimento, reflexões estas que direcionavam às novas ações. 
Com a intenção de buscar elementos para construir a resposta à indagação formulada, inicialmente utilizou-se os seguintes instrumentos para realizar a coleta de dados: observações por meio de acompanhamento das atividades, das teorias utilizadas para respaldar as práticas dos bolsistas, as diferentes metodologias empregadas; análise dos documentos produzidos pelos bolsistas (planejamentos, relatórios). Além desses instrumentos, foram analisadas as reflexões dos bolsistas buscando relações entre teoria e prática no decorrer do processo.

\section{Resultados da pesquisa}

No que se refere aos eixos básicos que foram desenvolvidos pelos bolsistas, ressalta-se que para a realização da pesquisa histórica e contextual tanto da identidade do professor de matemática quanto da própria escola, os bolsistas realizaram levantamentos e análise de documentos escritos, depoimentos orais e escritos de professores, alunos, administradores, demais membros da comunidade escolar, pais e egressos. Pelos instrumentos elaborados, os bolsistas conseguiram:

- registrar a história da escola, caracterizando a sua relação com a comunidade local e compreender como as políticas públicas vêm intervindo na escola no que se refere à estrutura administrativa e pedagógica (particularmente ao ensino da matemática). A identificação de professores que atuaram no ensino da matemática desde a criação da Escola juntamente com o estudo de documentos tais como Projetos Políticos Pedagógicos, diários de classe, provas, relatórios de projetos e eventos realizados, atas de reuniões, dentre outros, e ainda a análise de entrevistas realizadas com a equipe técnico-pedagógica ajudaram a identificar "fragmentos" para registrar essa história. Com as entrevistas realizadas com a equipe técnico-pedagógica da Escola, com membros da comunidade e alunos os bolsistas constataram que a Escola atende algumas das expectativas profissionais da comunidade com a oferta de alguns cursos técnicos/profissionalizantes e eventos sociais, culturais e educativos dos quais a comunidade participa. Buscando contextualizar em nível nacional a história registrada, os bolsistas estudaram textos sobre políticas públicas educacionais, a história da educação e do ensino da matemática no Brasil, traçando um paralelo entre elas. E, para que os bolsistas do PIBID-Matemática entendessem a estrutura atual de funcionamento da escola, enquanto instituição de ensino, eles estudaram e analisaram o Projeto Político Pedagógico (PPP) da escola em vigor, identificaram as funções e atribuições da secretaria, da direção, da supervisão, dos conselhos de classe, do conselho escolar e a relação que a escola mantém com a comunidade. Estas informações auxiliaram os bolsistas a traçar o perfil da escola pesquisada.

- Traçar o perfil dos professores de matemática da escola nos aspectos de formação, participação em eventos da área de atuação, motivos da escolha profissional e da área de conhecimento, experiência docente, projetos educacionais desenvolvidos ao longo da profissão, participação em atividades promovidas pela escola, dificuldades e facilidades na atuação profissional. Para melhor compreender o perfil traçado tiveram a necessidade de estudar teorias que versam sobre a formação de professores no Brasil.

- Traçar o perfil dos alunos nos aspectos social, econômico, cultural e de conhecimento matemático. Esse perfil teve por objetivo auxiliar os bolsistas no planejamento e desenvolvimento das ações pedagógicas posteriormente realizadas na Escola, em virtude de ter evidenciado facilidades e dificuldades dos alunos com o conhecimento matemático. Isso 
levou os bolsistas a estudarem textos que discutem dificuldades no ensino e na aprendizagem da matemática, bem como tendências atuais para o ensino da mesma.

No que se refere aos aspectos pedagógicos, refletindo sobre o contexto atual da escola e da comunidade na qual está inserida, o perfil dos professores de matemática e dos alunos, os bolsistas planejaram e desenvolveram ações, junto aos alunos da escola, num trabalho colaborativo entre si, com o coordenador e com o supervisor. As ações foram: monitoria ao professor de matemática em sala de aula, monitorias contra turno individuais ou em grupos, oficinas pedagógicas, produção de Blog's educacionais, produção de boletim impresso denominado Fanzine, projeto Matemática com Pipoca.

A monitoria ao professor de matemática em sala de aula consistiu na participação do bolsista junto ao professor no planejamento de ensino anual, nos planejamentos de aulas e acompanhamento do desenvolvimento dos mesmos em sala de aula atuando como monitor do professor. Com esta atividade os bolsistas tiveram a oportunidade de conhecer os alunos, nos aspectos de comportamento e de domínio de conteúdo, com os quais trabalhariam sozinhos em outras ações previstas. As reflexões sobre o processo de ensino e aprendizagem vivenciado em cada aula, bem como a participação dos alunos e suas próprias atuações como monitores, considerando inclusive as facilidades e dificuldades no trato aos alunos e domínio de conteúdo auxiliaram sobremaneira na atuação nas demais aulas e no planejamento e desenvolvimento de ações futuras.

Analisando as reflexões coletivas envolvendo bolsistas, supervisor e coordenador ficou evidente pelos relatos que os bolsistas perceberam que não bastaria somente o domínio de conteúdo, mas também domínio das teorias da aprendizagem e domínio de classe, que passa pelo conhecimento da psicologia da educação. Os bolsistas começam a estabelecer conexões entre as teorias estudadas na universidade e a utilização destas na prática, na tentativa de amenizar os problemas detectados em sala de aula.

As monitorias de atendimento individual ou em grupos ocorreram no contra turno escolar. O objetivo dessas era suprir as dificuldades de conteúdos matemáticos dos alunos da escola. Para algumas monitorias era o supervisor quem indicava os alunos que deveriam participar em função de suas dificuldades em matemática, em outras os próprios alunos é que se inscreviam. Os conteúdos trabalhados nessas monitorias eram determinados pelos professores em conjunto com bolsistas que também ficavam atentos às dificuldades dos alunos em sala de aula. Nas monitorias em grupo eram trabalhados conteúdos matemáticos que não necessariamente estavam sendo estudados em sala de aula, já as monitorias individuais eram usadas para que os alunos pudessem tirar dúvidas dos conteúdos matemáticos que estavam sendo trabalhados pelo professor em sala de aula. Para o desenvolvimento dessas monitorias os bolsistas, que sempre trabalharam em grupos, elaboravam planejamentos e produziam textos de apoio que seriam distribuídos aos alunos, bem como produziam ou reproduziam materiais manipuláveis. Todas estas produções eram avaliadas pelo supervisor e pelo coordenador. Durante o desenvolvimento das monitorias os bolsistas utilizavam fichas de acompanhamento nas quais registravam os conteúdos desenvolvidos no dia e as dúvidas dos alunos atendidos e a forma como estas foram trabalhadas. Sempre após os momentos de monitoria o grupo se reunia na Universidade para refletir sobre a prática desenvolvida, trocar informações sobre os registros efetuados nas fichas e o replanejamento das próximas monitorias.

As oficinas pedagógicas tinham como objetivo o desenvolvimento de temas matemáticos específicos por meio de diferentes recursos didáticos, tais como materiais manipuláveis, multimeios/multimídias, aulas de campo, atividades interdisciplinares, valendo-se das diferentes tendências da educação matemática, dentre elas história da 
matemática, resolução de problemas, jogos, informática educativa. Para as oficinas eram os bolsistas, organizados em duplas, que escolhiam os temas, algumas vezes com base em informações obtidas com alunos e professores da escola. Eram eles também que determinavam as partes do conteúdo que seriam trabalhadas e, a partir dai, passavam a pesquisar estratégias metodológicas e tendências da educação matemática que poderiam ser utilizadas para então elaborarem os planejamentos e confeccionarem os materiais necessários. Nessas oficinas, a intenção era primeiramente trabalhar a construção de conceitos matemáticos a partir dos materiais didáticos, numa perspectiva interacionista, para então fazer a sistematização do conhecimento matemático. De uma forma geral, as oficinas se caracterizavam como momentos de muita produção de conhecimento, com muita empolgação e participação dos alunos da escola nas atividades. As oficinas eram ofertadas semestralmente na escola, às vezes durante a semana no contra turno e outras vezes em eventos específicos da matemática ou integrados a outras áreas de conhecimento, nos sábados, período matutino e vespertino, com carga horária de 8 horas. Levando em consideração que eram várias as oficinas, os alunos da escola se inscreviam na que mais the interessava. A atuação nas oficinas propiciou uma reflexão sobre a prática no sentido do bolsista se avaliar enquanto profissional docente que se responsabiliza por todas as etapas do processo de ensino e aprendizagem, ou seja, planejamento, produção de materiais, desenvolvimento, tomadas de decisões, mudança do planejamento no decorrer da oficina e avaliação. Os bolsistas também refletiram sobre os motivos que não permitiram o desenvolvimento integral do planejamento de algumas oficinas e apontaram as reformulações necessárias para uma próxima oferta.

Observando as monitorias e oficinas e analisando as reflexões feitas pelos bolsistas pode-se perceber que ao longo do processo os mesmos foram sentindo necessidade de se aprofundarem em conteúdos matemáticos e a pesquisarem metodologias diferenciadas que propiciassem a (re)construção do conhecimento tanto deles quanto dos alunos da escola, caracterizando a busca por teorias que pudessem auxiliar ou melhorar a sua prática docente. Foi perceptível que neste contexto, não há a dicotomia entre teoria e prática, diferentemente do que normalmente ocorre nos cursos de graduação onde professores apresentam teorias que nem sempre serão as necessárias e/ou suficientes na prática. Essa dicotomia muitas vezes acontece porque o professor da graduação não tem convívio direto com a escola de ensino básico, como o proporcionado pelo Pibid.

As ações acima descritas foram proporcionando conhecimentos aos bolsistas e assim foram se constituindo enquanto profissionais docentes e acabaram sendo incentivados a pensar em outras ações que contemplassem experiências que se transformaram em atividades contínuas tomando características de subprojetos educacionais. Um deles denominado "Produzindo e comunicando matemática através de Blog's" tendo como objetivos: implementar tecnologias educacionais na rede de ensino e no processo de formação de professores de matemática; difundir novos formatos de apresentação e sistematização do conhecimento matemático; e possibilitar vivências que contribuam para o surgimento de novas linhas de pesquisa em educação matemática. Na escola os bolsistas ministraram cursos para professores e alunos para a criação e manutenção de Blog's, como ferramenta pedagógica, com a intenção de fomentar a expansão do conhecimento matemático reconstruído e divulgado por alunos e/ou professores.

Outro projeto denominado "Matemática em Fanzine" consistiu na produção de boletim impresso, elaborado pelos bolsistas com a participação de alunos da escola, cujo objetivo era que os alunos passassem a enxergar a matemática para além dos limites dos conteúdos expressos nos livros didáticos e contexto da escola, além de explorarem diferentes 
possibilidades de relações entre linguagem matemática e outras linguagens. O Fanzine é diferente de um boletim convencional, pois se caracteriza como uma publicação que expressa, articulando diferentes linguagens, o pensamento de seus autores sem restrições. O principal recurso é a criatividade e originalidade na abordagem de diferentes temáticas. Foram produzidos Fanzines abordando os seguintes temas: "Por que não somos os campeões em educação?", "Desafios matemáticos", "O aluno precisa de informação para refletir?", "Matemática e poder aquisitivo", "O custo da tecnologia", dentre outros.

O terceiro projeto denominado "Matemática com Pipoca" tinha por objetivo realizar sessões de vídeos, geralmente documentários, que apresentassem temas que oportunizassem observar e analisar informações, conceitos e conhecimentos envolvendo aspectos das ciências naturais, sociais, filosóficas e tecnológicas. Cada documentário gerou um conjunto de atividades práticas diferenciadas baseadas nos temas propostos que foram desenvolvidas pelos alunos da escola.

Acompanhando as discussões e planejamento das atividades do projeto "Matemática com Pipoca" pode-se perceber a necessidade dos bolsistas de realizarem pesquisas em outras áreas de conhecimento que pudessem subsidiar discussões e atividades interdisciplinares a partir dos documentários apresentados. Nas reflexões de avaliação do processo os bolsistas evidenciaram ter melhor compreensão das teorias já estudadas sobre interdisciplinaridade e a necessidade de contato com profissionais de outras áreas, visando estabelecer novas relações entre elas e/ou ampliar conhecimentos.

Apesar dos três projetos não caracterizarem atividades regulares inerentes ao currículo oficial da escola, estes proporcionaram diversos momentos de reflexão e muito estudo, contribuindo para a constituição do bolsista enquanto profissional docente.

\section{Considerações finais}

Pelo estudo realizado pode-se perceber que as ações realizadas pelos bolsistas do Pibid-Matemática/UFMT-Cuiabá foram relevantes por ter propiciado:

- ampliação do espaço de conhecimento teórico e prático, considerando as experiências desenvolvidas no período de atuação no programa, sendo propiciadas oportunidades de criação e participação em experiências metodológicas, tecnológicas e práticas docentes de caráter inovador e interdisciplinar visando a superação de problemas identificados no processo de ensino e aprendizagem;

- vivência no campo de trabalho, que significa se inserir no cotidiano da escola com uma visão de futuro professor e não mais como aluno da escola de ensino médio;

- contar com o acompanhamento de um professor-supervisor da escola que desempenhou papel de co-formador ao fazer a mediação entre os bolsistas e os alunos da escola no decorrer do processo;

- desenvolvimento de ações colaborativas que contribuíram para a formação dos membros do subprojeto, na medida em que a reflexão sobre a atuação de cada um foi importante e fortaleceu as ações em grupo;

- iniciação como professores pesquisadores de sua prática, possibilitando compreender o significado da reflexão antes, durante e após a prática educativa;

- validar a escolha profissional no sentido de se identificarem ou não como docentes; 
- maior segurança e autonomia, ao atuarem também no estágio supervisionado, para planejar aulas, desenvolvê-las e avaliá-las, bem como serem mais sensíveis para identificar facilidades e dificuldades dos alunos em relação ao conhecimento matemático.

No que se refere aos alunos da escola foram percebidas, pelos bolsistas, mudanças atitudinais (em termos de comportamento em relação à matemática) em momentos distintos do processo educacional: nos trabalhos em aulas regulares alguns alunos demonstravam certa apatia e desinteresse sobre os assuntos trabalhados enquanto que nas oficinas pedagógicas, monitorias no contra turno e projetos desenvolvidos os mesmos alunos demonstravam uma postura participativa e colaborativa, mostrando interesse e dedicação.

Pelas reflexões realizadas, algumas hipóteses foram levantadas para justificar estas mudanças atitudinais. $O$ fato de ter aula em outros espaços que não seja sua sala de aula, como, por exemplo, salão de eventos, sala de vídeo, biblioteca, quadra de esportes, laboratório de informática, pátio da escola, praça pública em frente da escola, pode caracterizar uma motivação; nas monitorias em contra turno, diferentemente da sala de aula, o que importava era trabalhar exclusivamente as dificuldades de conteúdos matemáticos apresentadas pelos alunos que acabavam se sentindo valorizados; nas oficinas os conteúdos não eram impostos aos alunos tendo em vista que estes tinham a liberdade de se inscreverem nas oficinas de seu interesse, além disso, nestas oficinas as metodologias utilizadas eram muito variadas e atrativas aos alunos; nos projetos os alunos se sentiam protagonistas nas ações desenvolvidas. Como consequência dos trabalhos realizados as notas dos alunos em matemática melhoraram significativamente e professores deram depoimentos de que alunos que eram totalmente apáticos nas aulas passaram a participar ativamente das mesmas.

Ter acompanhado e observado os bolsistas nas diversas ações desenvolvidas na escola, recorrendo aos momentos de reflexões, às observações e depoimentos dos bolsistas referentes aos diferentes momentos do processo e aos documentos produzidos possibilitou perceber que: os bolsistas com o passar do tempo foram se constituindo em profissionais docentes com a característica de professores reflexivos, uma vez que foram exercitando a prática da investigação de sua própria ação docente, identificando suas limitações e deficiências e buscando superá-las por meio de teorias e reflexões individuais e no coletivo. Dessa forma, foram ao longo do processo (re)construindo reflexivamente seus saberes teóricos e práticos.

Levando em consideração que o estágio supervisionado na graduação é distribuído nos três últimos semestres, contando com uma carga horária de 400 horas, não é possível que os alunos possam vivenciar a escola de ensino básico em sua essência. Diferentemente a isso, no Pibid o aluno da graduação começa a vivenciar a escola já no início do curso, participando das mais variadas ações desenvolvidas na mesma, conhecendo com mais propriedade seu cotidiano e tendo possibilidade de desenvolver atividades, como as citadas neste trabalho, que complementam o estágio supervisionado e diminui a dicotomia entre teoria e prática.

Além de contribuir para o incentivo do aluno à docência e para a sua constituição enquanto profissional docente, o Pibid-Matemática tem contribuído não só para a formação continuada dos professores supervisores, mas também dos professores universitários (coordenadores de área no Pibid). 


\section{Referências}

BRASIL, Conselho Nacional de Educação. Parecer normativo no 009/2001, de 08 de maio de 2001. Diretrizes Curriculares Nacionais para a formação de professores da educação básica, em nível superior, curso de licenciatura, de graduação plena. Diário Oficial [da] República Federativa do Brasil, Poder Executivo, Brasília, DF, 18 jan. 2002. Seção 1, p. 21.

CANDAU, V. M.; LELIS, I. A. A relação teoria-prática na formação do educador. In: CANDAU, V. M.; LELIS, I. A. (Org.). Rumo a uma nova didática. 8 ed., Petrópolis-RJ: Vozes, 1996.

CASTRO, M. A. C. D. Abrindo espaço no cotidiano para o estágio supervisionado - uma questão do olhar e da relação - na formação inicial e em serviço. Tese (Doutorado). 230. Pontifícia Universidade Católica de São Paulo - PUC-SP, 2000.

FREITAS, H. C. L. de. O trabalho como princípio articulador na prática de ensino e nos estágios. Campinas, SP: Papirus, 1996.

GÓMEZ, A. A função e a formação do professor / a no ensino para a compreensão: diferentes perspectivas. In: SACRISTÁN, J. G.; GÓMEZ, A. Compreender e transformar o ensino. Porto Alegre: Artes Médicas, 1995.

NACARATO, A. M.; PAIVA, M. A. V. A formação do professor que ensina matemática: estudos e perspectivas a partir das investigações realizadas pelos pesquisadores do GT 7 da SBEM. In: NACARATO, A. M.; PAIVA, M. A. V. (Orgs.) A formação do professor que ensina matemática: perspectivas e pesquisas. Belo Horizonte: Autêntica, 2006.

PICONEZ, S. A prática de ensino e o Estágio supervisionado. Campinas-SP: Papirus, 1991.

RAMOS, S. A pesquisa educacional inserida na formação inicial e continuada de professores: superando o distanciamento entre a universidade e a escola. Unopar Cientifica: Ciências Humanas e Educação. Londrina: v. 6, n. 1, p. 65-68, jun. 2005. Disponível em <http://www12.unopar.br/unopar/pesquisa/rcArtigos.action>. Acesso em 02 out. 2012.

SCHÖN, D. A. Formar professores como profissionais reflexivos. In: Nóvoa, A. Os professores e sua formação. Lisboa: Publicações Dom Quixote, 2 edição, 1995. 